\title{
ALÉM DAS GRADES: UM ESTUDO DE CASO SOBRE AS ESTRATÉGIAS UTILIZADAS PARA INTEGRAÇÃO DOS PRESÍDIOS ÀS REDES TERRITORIAIS EXTERNAS DO TRÁFICO DE DROGAS
}

Roberto Magno Reis Netto ${ }^{1}$ Clay Anderson Nunes Chagas ${ }^{2}$

Resumo: O presente trabalho objetivou a realização de um estudo de caso instrumental para compreensão de como as estratégias utilizadas para integração dos presídios às redes territoriais externas do tráfico de drogas condicionaram as relações de territorialidade de um determinado bairro do município de Ananindeua PA. Valendo-se do método hermenêutico e dialético, bem como de técnicas de estudo de caso, pesquisa documental e cartografia temática, perfez-se a análise do caso denominado operação paradigma para verificação do objetivo proposto. Como resultado, constatou-se que 0 uso das estratégias em questão influenciou diretamente as relações de territorialidade havidas na escala do estudo sob diversas perspectivas, confirmando e negando algumas proposições constantes da teoria, do mesmo modo acrescentando dados até então não enunciados em estudos sobre 0 tema.

Palavras-chave: Tráfico de drogas. Presídios. Estratégias e mediatos. Territorialidade. Estudo de caso.

\section{BEYOND THE GRIDES: A CASE STUDY ON THE STRATEGIES USED TO INTEGRATE THE PRESIDENCIES FOR EXTERNAL TERRITORY NETWORKS OF DRUG TRAFFICKING}

Abstract: The present work aimed to conduct an instrumental case study to understand how the strategies used to integrate the prisons into the external territorial networks of drug trafficking conditioned the territoriality relations of a certain neighborhood of Ananindeua - PA. Using the hermeneutic and dialectical method, as well as case study techniques, documentary research and thematic cartography, the analysis of the case called operation paradigm was verified to verify the proposed objective. As a result, it was found that the use of the strategies in question directly influenced the territoriality relations in the scale of the study from different perspectives, confirming and denying some constant propositions of the theory, as well as adding data not previously mentioned in studies on the theme.

Keywords: Drug trafficking. Prisons. Strategies and mediates. Territoriality. Case study.

\section{ALLÁ DE LAS REJILLAS: UN ESTUDIO DE CASO SOBRE LAS ESTRATEGIAS UTILIZADAS PARA INTEGRAR LAS PRISIONES EN LAS REDES TERRITORIALES EXTERNAS DEL NARCOTRÁFICO}

Resumen: El presente trabajo tuvo como objetivo realizar un estudio de caso instrumental para comprender cómo las estrategias utilizadas para integrar las cárceles en las redes territoriales externas del narcotráfico condicionaron las

\footnotetext{
${ }^{1}$ Universidade Federal do Pará, Programa de pós-graduação em Geografia, Belém-PA, Brasil, Bob_reis_ufpa@yahoo.com.br, http://orcid.org/0000-0002-5076-6149.

${ }^{2}$ Universidade Federal do Pará, Programa de pós-graduação em Geografia, Belém-PA, Brasil, Claychagas@ufpa.br, http://orcid.org/0000-0002-4223-0192.
} 
relaciones de territorialidad de cierto vecindario de Ananindeua - PA. Utilizando el método hermenéutico y dialéctico, así como técnicas de estudio de casos, investigación documental y cartografía temática, se verificó el análisis del caso denominado paradigma de operación para verificar el objetivo propuesto. Como resultado, se encontró que el uso de las estrategias en cuestión influyó directamente en las relaciones de territorialidad en la escala del estudio desde diferentes perspectivas, confirmando y negando algunas proposiciones constantes de la teoría, así como agregando datos no mencionados previamente en estudios sobre el tema.

Palabras clave: Narcotráfico. Prisiones Estrategias y mediates. Territorialidad. Estudio de caso.

\section{Introdução}

Após assistir o surgimento das facções criminosas no final da década de 1970, bem como sua consolidação e expansão ao longo da década de 1990 e início da década de 2000, atualmente, o Brasil observa, sob relativa sensação de impotência, mostras do poderio dessas organizações em rebeliões constatadas em vários Estados ao fim desta segunda década do século XXI.

O início do ano de 2017 foi marcado por revoltas amplamente noticiadas em Estados como São Paulo, Rio de Janeiro, Rondônia, Pará, Roraima, Amazonas e Rio Grande do Norte (UOL, 2017), situação que se repetiu no ano de 2018, no Estado de Goiás (UOL, 2018), ao passo que, desde setembro de 2017, os governos assistiram a uma guerra entre facções rivais pelo domínio do tráfico de drogas em morros do Rio de Janeiro (O GLOBO, 2017) ainda sem sinais de solução. O mais interessante, em todos os casos, é que foi apontado pela Administração Pública de vários destes Estados que as ações teriam sido deflagraras sob a reconhecida participação de lideranças do tráfico que se encontrariam encarceradas.

Dos mencionados fatos, reiteradamente, tem-se percebido que 0 encarceramento de agentes territoriais do tráfico não tem mostrado sucesso no desmantelamento de redes e relações de poder havidas fora da cadeia, sobretudo, em razão do caráter rentável dessa atividade e da existência de um mercado à espera de suas ofertas (RODRIGUES, 2004; DIAS, 2013; REIS NETTO; CHAGAS, 2018b).

Questionando a respeito das estratégias que seriam utilizadas pelos agentes territoriais do tráfico de drogas para integração dos presídios às redes territoriais externas, por intermédio de trabalho desenvolvido junto ao Programa de PósGraduação em Segurança Pública da Universidade Federal do Pará (com apoio do Laboratório de Pesquisa em Geografia da Violência e do Crime/UEPA e do Grupo de Pesquisa Métodos de Diagnóstico em segurança Pública/UFPA), constatou-se que 
os criminosos se utilizariam de seis conjuntos de ações destinadas à referida integração, as quais, manejadas de forma simultânea e intercruzada (DIAS, 2013), consistiriam: a) no estabelecimento/manutenção de redes e relações entre os agentes sintagmáticos internos ao cárcere; b) no estabelecimento/manutenção de relações e cooptação de agentes do sistema penitenciário; c) na utilização de mediatos para comunicação a partir do cárcere, no estabelecimento/manutenção de redes e relações junto a agentes sintagmáticos públicos ou privados externos ao cárcere; d) no estabelecimento de redes comerciais internas do tráfico de drogas; e, por fim, e) no enfrentamento direto de agentes sintagmáticos e atingimento símbolos vinculados ao poder público (REIS NETTO, 2018; REIS NETTO; CHAGAS, 2018b).

Contudo, como ainda se afigurava relevante a realização de aproximações empíricas sobre o fenômeno, o estudo prosseguiu com a análise da percepção de agentes da segurança pública do Estado do Pará a respeito das referidas estratégias (REIS NETTO; CHAGAS, 2018a, 2019a, 2019b), e, especificamente neste trabalho, se dedicou à realização de um caso concreto, no sentido de observar a aplicação prática daquelas estratégias e as consequências territoriais decorrentes de sua implementação.

Desta feita, novamente inspirado na teoria territorial de Raffestin (1993), o presente trabalho objetivou a realização de um estudo de caso instrumental, para compreensão de como a utilização, simultânea e intercruzada (DIAS, 2013), das estratégias em questão (REIS NETTO, 2018) condicionaram as relações de territorialidade do bairro de Águas Lindas no município de Ananindeua - PA no período do ano de 2016. Para tanto, tornou-se necessária a explicação de contornos teóricos e metodológicos adotados pelo estudo, questão da qual se ocuparam as seções seguintes.

\section{Desenvolvimento}

\section{Referencial Teórico}

Primeiramente, para compreensão do fenômeno chamado tráfico de drogas, mostrou-se necessária a superação de sua imprecisa visão jurídico-legal, determinada por proibições historicamente influenciadas por uma política internacional de guerra às drogas, que, embora detivesse em seu discurso oficial um propósito de proteção da saúde pública, na prática, apenas acabou por promover a concentração do monopólio e utilização de substâncias ditas entorpecentes nas 
mãos de grupos hegemônicos, notadamente a indústria farmacêutica, dos países que encabeçaram esse movimento (RODRIGUES, 2004; D’ÉLIA FILHO, 2014).

A aplicação concreta dos limitados mecanismos legislativos da lei antidrogas (a lei 11.343/06), que, em seus artigos 33, 34, 37 e 38, perfez uma tentativa de proibir toda uma cadeia produtiva e comercial de entorpecentes (CARVALHO, 2016), por sua vez, acabou por consagrar um atingimento seletivo dos setores mais visíveis do tráfico, notadamente, os revendedores e pequenos investidores sem, com isso, desmantelar os oligopólios responsáveis pela articulação da atividade e concentração dos lucros em um nível nacional e transnacional (D'ÉLIA FILHO, 2014). De maneira especial, a repressão ao tráfico acabou por recair, preponderamente, sobre zonas pobres e estigmatizadas das cidades, promovendo uma desterritorialização precária (HAESBAERT, 2014) de grandes contingentes populacionais ao contexto do cárcere sem, no entanto, garantir qualquer contrapartida prática de reinserção social (DIAS, 2013; D'ÉLIA FILHO, 2014).

Sufragados pelas condições vividas nas prisões, muitos destes agentes territoriais se viram desafiados a permanecer na economia do crime (AMORIM, 2011; 2015; DIAS, 2013) que, àquela altura, Ihes representava uma forma de inclusão numa sociedade de consumo materialista (BAUMAN, 1998), passando a adotar, com isso, formas de resistência (RAFFESTIN, 1993) à quebra de suas relações com o território originário e ao encarceramento.

No Brasil, esse fenômeno foi apontado como um fator determinante para o surgimento das facções do crime organizado, a partir do final da década de 1970 (RODRIGUES, 2004), que, já na década de 1980, adotaram o tráfico de drogas como sua principal atividade (DIAS, 2013; D'ÉLIA FILHO, 2014; AMORIM, 2011; 2015).

E, para se manter em integração, mesmo no cárcere, com o circuito externo do tráfico de drogas, os agentes territoriais da atividade passaram a se valer de determinadas estratégias (conjuntos de ações planejadas) e mediatos (meios, instrumentos, utilizados para viabilização de seus planos) (RAFFESTIN, 1993) que, paralelamente à ineficácia das ações repressivas do Estado em seu enfrentamento, conseguiram impor sua vontade além das grades (REIS NETTO, 2018).

Diante desta complexidade social, portanto, se mostrou muito mais prudente interpretar o fenômeno do tráfico de drogas como algo análogo a uma atividade empresarial (CHAGAS, 2014) a despeito de sua ilicitude. Ao passo, seus atores seriam caracterizáveis como verdadeiros agentes sintagmáticos, ou seja, que 
trabalhariam conforme planos de poder estabelecidos) (RAFFESTIN, 1993), cuja ação estaria voltada à expansão, consolidação e manutenção de territórios comerciais em contraposição à postura proibitiva do Estado.

Por meio de relações de poder estabelecidas entre esses agentes e um espaço (dado originário), por sua vez, seriam constituídos os territórios do tráfico em existência simultânea a vários outros territórios e agentes, que, em interação ora simbiótica, ora conflituosa, constituiriam relações de territorialidade ou de multiterritorialidade (HAESBAERT, 2014) condicionantes do espaço e condicionadas pelo mesmo (RAFFESTIN, 1993). Assim, as estratégias manejadas pelos agentes sintagmáticos em um determinado território, constituído a partir do espaço, moldariam e influenciariam a (multi)territorialidade ali existente, ou seja, o processo de existência e interação entre diversos territórios e agentes das mais diversas espécies (RAFFESTIN, 1993; HAESBAERT, 2014).

Contudo, essa conclusão também impôs a necessidade de superação da interpretação zonal de território (RAFFESTIN, 1993), preponderante na lógica estatal. Além de constituir territórios zonais em constante fluidez, por conta das relações de poder desenvolvidas no espaço, as estratégias manejadas pelos agentes territoriais também propiciariam o surgimento de territórios-rede, representados por diferentes nós ligados no espaço, e de territórios simbólicos, que se ligariam a seus agentes por relações de afetividade aos locais (HAESBAERT, 2014).

Esses preceitos teóricos foram de fundamental valia para a compreensão de questões como a existência de presídios pertencentes a determinadas facções (em verdade territórios-zona), territórios pertencentes a grupos criminosos ligados a lideranças encarceradas, que mesclam as lógicas zonais e reticulares e, ainda, de áreas controladas por facções, que além de envolverem aspectos zonais e reticulares, especialmente, representam territórios simbólicos ligados às organizações.

Como mencionado ao início, em esforço de revisão literária, inferência e categorização das espécies, restou identificado que os agentes territoriais do tráfico, por sua vez, se valeriam de seis estratégias para promover a vinculação do cárcere a suas redes territoriais externas (REIS NETTO, 2018; REIS NETTO; CHAGAS, 2018b).

Primeiramente, identificou-se que o estabelecimento e a manutenção de redes e relações entre os agentes sintagmáticos internos ao cárcere, representaria 
um conjunto de ações voltadas à integração de lideranças e população prisional (esta, um trunfo de poder) (RAFFESTIN, 1993), bem como de controle de comportamentos e estabelecimento de um equilíbrio interno fundamental à organização de grupos criminosos, garantindo, com isso, a possibilidade de vinculação das prisões ao ambiente externo (REIS NETTO; CHAGAS, 2019a). A integração se concretizaria, ainda, por meio do estabelecimento e manutenção de redes e relações junto a agentes sintagmáticos públicos ou privados externos ao cárcere, que, sob diversas formas, fariam valer, no mundo externo, os planos sintagmáticos das lideranças e grupos encarcerados (REIS NETTO; CHAGAS, 2018a).

Para tornar mais eficientes essas redes, seria adotada como estratégia, também, a utilização de mediatos para comunicação a partir do cárcere, garantida por uma série de medidas voltadas a viabilizar a construção de canais comunicativos com o mundo externo. Além disso, mostrou-se significativo o estabelecimento e manutenção de relações e cooptação de agentes do sistema penitenciário, como forma de aproveitamento de uma rede híbrida (interna e externa) de agentes contextualmente mais próximos dos traficantes encarcerados, mediante diversas formas de cooptação.

Constatando, igualmente, que o âmbito do cárcere também se afigurava como um comércio em potencial, assim como que a droga representava não só uma importante moeda de troca, senão, um verdadeiro instrumento de poder, adotou-se como estratégia o estabelecimento de redes comerciais internas do tráfico de drogas, que viabilizaria a instalação de uma considerável rede comercial dentro do cárcere.

E, por fim, seja para demonstração de poder, seja para forçar o estado à adoção de medidas de interesse dos agentes do tráfico no cárcere ou, sobretudo, para restabelecer fluxos e redes, evidenciou-se a adoção de estratégias de enfrentamento direto de agentes sintagmáticos e atingimento símbolos vinculados ao poder público, como genuína tática de guerra (REIS NETTO; CHAGAS, 2019b).

No entanto, como dito acima, indo além da identificação daquelas estratégias (atividade teórica) e como forma de concreta contribuição aos problemas enfrentados pela segurança pública (especialmente na base territorial deste estudo, - Estado do Pará), afigurou-se necessária a compreensão de como aquelas poderiam repercutir atividade empírico-pragmática nas relações territoriais havidas 
num determinado tempo e espaço (REIS NETTO, 2018; REIS NETTO; CHAGAS, 2018).

Para tanto, sob o referencial ora elencado, este trabalho se propôs à realização do estudo de um caso concreto, onde se evidenciou a ação de grupos vinculados a uma facção de extensão nacional (o Comando Vermelho - CV) no âmbito do bairro de Águas Lindas, município de Ananindeua-PA, vinculado à região metropolitana do Estado do Pará. Antes da análise prática dos postulados da pesquisa, no entanto, foi de suma importância a delineação dos aspectos metodológicos e técnicos que circunscreveram o estudo, conforme se expôs a seguir.

\section{Métodos e técnicas}

Para atingimento do objetivo proposto, 0 estudo adotou 0 método hermenêutico e dialético (STEIN, 1983; HABERMAS, 1987; MINAYO, 2002), caracterizado como proposta que toma a linguagem como ponto de partida, sem olvidar, no entanto, que esta é condicionada por aspectos sociais, econômicos, políticos e históricos em que é emitida, se apresentando, assim, como uma linguagem sistemicamente perturbada (HABERMAS, 1987), que, para ser apreendida, depende de uma atividade que desvele as relações de poder que a permeiam.

A escolha se justificou, por sua vez, em razão da complexidade inerente ao objeto de estudo, o fenômeno do tráfico de drogas, em especial, em função da complexidade linguística das fontes de estudo, conforme se argumentou adiante.

Por sua vez, para garantir a atividade de depuração da essência linguística, seguiu-se a recomendação de Minayo (2002, 2005) de respeito às fontes, consideração dos aspectos históricos das mensagens e consideração da intencionalidade dos emissores, seguida, por sua vez, de uma atividade de triangulação de dados interna com a teoria base do estudo (RAFFESTIN, 1993) e externa com a literatura previamente produzida sobre o tema.

Como a técnica principal da pesquisa foi o estudo de caso, conforme delineado adiante, a abordagem adotada foi qualitativa, focada, portanto, no conteúdo do fenômeno analisado, conforme o costume dessa prática (OLSEN, 2015).

Após aproximação de agentes territoriais da segurança pública, quando da realização de anterior pesquisa envolvendo suas percepções sobre as estratégias 
em comento, houve o contato dos pesquisadores com casos práticos envolvendo a vinculação territorial entre cárcere e redes externas do tráfico de drogas, que, por sua vez, motivaram o surgimento do objetivo deste trabalho, como consequência natural do aprofundamento da pesquisa. Optou-se, assim, pela realização de um estudo de caso, ou seja, a tomada de um esforço interpretativo voltado a um fenômeno constatado no universo empírico-analítico da pesquisa social, verificando peculiaridades de sua história, contexto e características (FREITAS; JABBOUR, 2011; VENTURA, 2007). Por conseguinte, de acordo com o objetivo proposto e diante do intento de compreensão prática de postulados teóricos previamente levantados, utilizou-se a espécie de estudo de caso denominada instrumental (VENTURA, 2007).

Embora, conforme ensinou Alvez-Mazzotti (2006), o caso a ser escolhido sempre represente o resultado de opções paradigmáticas dos pesquisadores, ainda assim, restaram preestabelecidos critérios de seleção recomendados pela autora, em análise a outros pesquisadores representativos da técnica: a) Prévia delimitação de um problema de pesquisa; b) A Escolha de um caso representativo da complexidade teórica em discussão e, por óbvio, bastante intrigante à sociedade e, consequentemente, à ciência; c) potencialidade de universalização de resultados a despeito da existência de eventuais peculiaridades.

Em razão disso, este estudo se propôs a uma atividade descritiva de relações de territorialidade identificadas em uma investigação criminal, doravante denominada operação paradigma, referente à apuração de crimes ocorridos no município de Ananindeua-PA, preponderantemente, mas não exclusivamente, no bairro das Águas Lindas entre os meses de janeiro e agosto de 2016.

O caso apresentou intensa repercussão na imprensa, no mundo da segurança pública e junto ao Poder Judiciário, especialmente, pela participação de diversos agentes territoriais locais, de grupos criminosos aliados externos à área e de agentes territoriais encarcerados, tanto em presídios estaduais, quanto federais, bem como pelas características das mortes causadas ao longo da atuação criminosa e, especialmente, pela provada vinculação ao tráfico de drogas.

Quanto aos aspectos éticos do estudo, cumpre assinalar, em primeiro lugar, que a operação já foi concluída e, atualmente, compõe peça informativa dos autos ação penal pública em andamento junto ao judiciário paraense, sendo, portanto, plenamente acessível (dado aberto) e livre de qualquer limitação legal ou administrativa quanto ao uso das informações constantes dos autos do inquérito ou 
do processo, haja vista a não decretação de segredo de justiça (conforme art. 792, do Código de Processo Penal Brasileiro ). Inclusive, o próprio sítio virtual do Tribunal de Justiça do Estado do Pará destaca algumas decisões proferidas neste processo como representativas da atuação desta colenda corte.

No entanto, mesmo diante da fácil identificação do caso e sujeitos da pesquisa em respeito aos nomes dos envolvidos, especialmente os mortos, sentimentos dos familiares e amigos, respeito às localidades envolvidas e, sobretudo, em respeito ao direito ao esquecimento (DIVINO; SIQUEIRA, 2017) dos acusados, optou-se pela não indicação de nomes, endereços, ou quaisquer dados identificadores, principalmente, por que o foco do estudo diz respeito ao fenômeno em si e não às pessoas (OLSEN, 2015), embora estas perpassem pelos fatos. Assim, os agentes territoriais serão identificados por siglas: ATEPF - Agente Territorial Encarcerado em Presídio Federal; ATEPE - Agente Territorial Encarcerado em Presídio Estadual; ATL - Agente Territorial em Liberdade; ATS Agente Territorial Subordinado; ATP - Agente Territorial Privado; e, ATM - Agente Territorial Morto pela organização.

Para execução do estudo, foi utilizada, primeiramente, uma ampla pesquisa documental sobre o inquérito policial da operação paradigma (fonte primária de análise) de forma paralela à consulta de peças processuais e notícias veiculadas nos jornais (fontes secundárias, utilizadas com desprezo à eventuais especulações não apontadas nos documentos) (LAKATOS; MARCONI, 2016). Optou-se pela não realização de entrevistas para evitar eventual deturpação das constatações do estudo e sua utilização como fonte no processo, ainda em andamento, inconveniente que já ocorreu noutras pesquisas jurídicas de casos polêmicos.

Para análise dos dados coletados, por sua vez, o estudo se inspirou no protocolo recomendado por Freitas e Jabbour (2011), com adaptações, inclusive, incentivadas pelos mesmos autores: a) Organização e descrição dos registros e evidencias coletadas; b) Análise das evidências à luz da literatura; c) triangulação interna e externa das fontes com a teoria fundante e literatura abarcada pelo estudo, conforme recomendado por Minayo (2005). Cumpre assinalar que a atividade de triangulação afigurou-se de fundamental importância, justamente, porque o inquérito, além de uma linguagem típica dos órgãos policiais envolvidos, igualmente, continha registros telefônicos de contatos entre os agentes territoriais do tráfico, com linguagem contendo significantes absolutamente diferenciados em uma mostra da natural complexidade do fenômeno e necessidade de tratamento linguístico. 
Por sua vez, a exposição dos resultados seguiu a proposta descritiva para comparação à teoria, já mencionada acima (VENTURA, 2007), utilizando-se, além da exposição escrita, de organograma explicativo da organização (Figura 1), bem como de uma representação cartográfica baseada em mapas temáticos (FITZ, 2008), elaborados a partir de dados constantes das mencionadas fontes de pesquisa e de levantamentos feitos presencialmente pelos pesquisadores no bairro, para uma melhor compreensão do fenômeno em estudo (MARTINELLI, 2014).

Para tanto, foram elaborados dois mapas temáticos. No primeiro (Figura 2) buscou-se estabelecer uma compreensão do território-zona de atuação da organização criminosa, tomando como escala o bairro das Águas Lindas, sede do grupo, no município de Ananindeua-PA entre os meses de janeiro e agosto de 2016, período em que as relações de poder foram identificadas pela operação, destacando pontos representativos dos domicílios dos agentes territoriais envolvidos na atividade do tráfico de drogas e outros crimes, relacionando-os com pontos representativos das mortes decorrentes das disputas de poder local, que puderam ser inequivocamente situadas no espaço. Salienta-se que, em respeito ao já destacado protocolo ético, a escala foi mantida a uma distância que não permitisse a perfeita identificação dos domicílios dos envolvidos e locais dos óbitos sem, entretanto, impossibilitar a compreensão dos fenômenos em estudo.

No segundo mapa (Figura 3) buscou-se a representação do território-rede da organização e sua clara vinculação com o cárcere, em interação com a área zonal estabelecida no primeiro mapa, tomando como escala a região metropolitana entre os meses de janeiro e agosto de 2016.

Utilizando destes recursos, a seção de resultados, a seguir, buscou a demonstração de como a utilização simultânea e intercruzada das estratégias manejadas pelo tráfico de drogas para integração dos presídios às redes territoriais externas influenciou a territorialidade do bairro das Águas Lindas no município de Ananindeua-PA ao longo do período de tempo em que a criminalidade foi acompanhada na operação de janeiro a agosto de 2016.

\section{Resultados e discussões}

\section{Breve histórico da operação paradigma}

A Operação Paradigma teve início a partir investigações em torno da morte de um militar estadual - ATM07 - em Janeiro de 2016, alvejado por cerca de trinta tiros, 
disparados por dois homens encapuzados em uma moto, dos quais vinte 0 atingiram. A arma do militar também foi roubada durante o crime.

A execução, ocorrida fora da área de influência da organização (delimitada adiante), por si só já caracterizava uma nítida demonstração de poder, tomando-se por base a quantidade de projéteis utilizados, e, de igual forma, chamou a atenção pelo fato de o militar ser acusado de vários crimes e do suposto envolvimento com milícias locais, dentre eles, dois assassinatos de supostos criminosos no bairro do Aurá, em Ananindeua-PA, contíguo ao bairro das Águas Lindas.

Iniciadas as investigações, apurou-se que o assassinato teria ocorrido como represália à ação territorial do militar contra os interesses de uma organização do tráfico de drogas local, cujos integrantes passaram a ser identificados progressivamente, em ações de campo desenvolvidas pela Polícia Civil.

Nesse interregno, várias mortes passaram a ocorrer progressivamente na área, sendo apontadas em relação aos mesmos integrantes da organização em questão: a) em 21.02.2016, um indivíduo (ATM01) foi assassinado a tiros, descobrindo-se, nas investigações, em razão de o mesmo ter cometido um furto contra parentes de um membro da organização e, sobretudo, por tê-lo identificado como traficante, na escala do estudo; b) dois dias depois, em 22.02.2016, registrouse a morte de mais dois indivíduos (ATM02 e ATM03), em razão de sua condição de seguranças locais, supostamente envolvidos com milícias da área; c) em 07.03.2016 constatou-se a morte de mais dois vigilantes locais (ATM 04 e ATM 05) dentro da escala do estudo, enquanto realizavam rondas num conjunto do bairro, supostamente, pelo envolvimento com milícias locais e, especialmente, por terem se oposto ao tráfico no local. Mais adiante, a organização ainda foi responsável pela morte: d) em 15.07.2016, uma jovem de 19 anos (ATM 08), que deteria dívidas junto à organização e que foi encontrada morta com vários tiros no interior da mata do Utinga, dentro dos limites do bairro do Curió-Utinga, contíguo à escala do estudo, cuja localização exata do local do óbito não foi precisada quando das visitas dos pesquisadores).

Em todos os casos, houve a utilização de números consideráveis de projéteis.

Desde o primeiro mês de investigação, instaurada ainda em janeiro de 2016, a Polícia Civil, sob autorização judicial, passou a realizar interceptações de linhas telefônicas identificadas como pertencentes à organização, a partir de trabalhos de campo, inclusive, chegando a tentar evitar algumas das mortes acima. 
A relevante constatação, no entanto, foi a de que os crimes estavam ligados a uma organização criminosa local, atuante, principalmente, no tráfico de drogas da escala do bairro e área contígua, a qual estava interligada a outras organizações de traficantes na Região Metropolitana de Belém, cujo principal líder se encontrava preso por outros crimes (ATEPE 03). Mesmo encarcerado, o líder comandava não só o comércio de drogas na área, como, especialmente, determinou a realização vários outros crimes e planos de expansão, sendo assim, sujeito determinante no estabelecimento dos planos sintagmáticos da organização. Ainda, contatou-se que o mesmo estava associado a outros elementos de alta periculosidade e afiliado à facção de extensão nacional Comando Vermelho - CV.

Durante o período da investigação, verificou-se que a organização, comandada a partir do cárcere, detinha amplo controle sobre o tráfico local, além de guardar consigo um amplo arsenal, pertencente ao Comando Vermelho - CV, à disposição para realização de medidas de violência e crimes. Ainda, evidenciou-se que o grupo se encontraria numa verdadeira guerra contra supostos milicianos e contra agentes da segurança pública na área.

O procedimento foi encerrado após a expedição, pelo Poder Judiciário, de vinte e cinco mandados de prisão preventiva, quatro de prisão temporária e vinte mandados de busca e apreensão, cumpridos em operação conjunta das Polícias Civil e Militar e Ministério Público no mês de agosto de 2016.

De uma análise aprofundada do caso, por sua vez, pode-se perceber que a aplicação simultânea e intercruzada (DIAS, 2013) das diversas estratégias identificadas na teoria (REIS NETTO, 2018), garantiram o sucesso temporário dos planos sintagmáticos da organização, condicionando significativamente as relações de territorialidade local (até intervenção da polícia), conforme se passa a expor.

\section{Da aplicação prática das estratégias e suas consequências em relação à territorialidade local}

Primeiramente, de uma ampla análise dos documentos relativos ao caso, foi possível constatar que o grupo detinha um nível de organização dentro do cárcere (Centro de Recuperação Penitenciária III - CRPP III na região de Americano, município de Santa Izabel do Pará, Região Metropolitana de Belém - PA), de onde a principal liderança do grupo (ATEPE 03) exarava as ordens e definia planos sintagmáticos de maneira associada a outros dois membros da quadrilha, dos quais, o primeiro estava preso na mesma cadeia (ATEPE 06) e o segundo num presídio 
existente em outro município (Presídio Estadual Metropolitano II - PEM II em Marituba-PA, também na Região Metropolitana de Belém - PA).

A associação, ainda, se estenderia a outros presos (ATEPE 01, apontado como líder do Comando Vermelho - CV no Estado do Pará e vinculado a outros crimes mencionados no inquérito; ATEPE 02, traficante paraense que deteria negócios com a quadrilha; e ATEPE's 04 e 05, identificados como comerciantes de drogas, que, igualmente, deteriam negócios com vários traficantes da Região Metropolitana de Belém - PA; todos presos no CRPPIII), que apoiariam a quadrilha em razão de sua inicial afiliação ao Comando Vermelho - CV, e que, foram destacados como detentores de grandes quantidades de armas e como nós pontos de união (RAFFESTIN, 1993) - ligados à redes para aquisição de drogas em um nível nacional, cujos produtos seriam destinados à venda dentre outros locais, na área do estudo.

Além disso, havia ainda outro associado que, ao longo da investigação, se encontrava preso na Penitenciária Federal de Catanduvas - PR (ATEPF 01), mas que, ainda assim, foi indiciado como responsável pelo controle sintagmático do tráfico local e coautor das mortes ocorridas, conjuntamente ao ATEPE 03, e que, certamente, se encontrava em condições de construir novas redes a partir daquele território, onde também se encontrava encarcerada a cúpula de diversas facções de extensão nacional, dentre elas, do Comando Vermelho - CV.

A seguir, se destacou um organograma da quadrilha e sua rede (Figura 1).

Estes fatos tornaram evidente que a estratégia de estabelecimento e manutenção de redes e relações entre os agentes sintagmáticos internos ao cárcere nos termos apontados pela literatura (AMORIM, 2011, 2015; DIAS, 2013; SAVIANO, 2014; TEIXEIRA, 2015), de fato, se afigurou como uma ação capaz de ampliar os poderes de uma organização local, alterando significativamente a territorialidade incialmente havida com sua zona comercial, uma vez que propiciou a consecução de novos contatos para aquisição de drogas e armas, desequilibrando as relações de poder em prol da satisfação dos planos sintagmáticos dos agentes do tráfico.

FIGURA 1 - Organograma da Organização Criminosa identificada como atuante no tráfico de drogas no Bairro das Águas Lindas, em Ananindeua-PA, ao longo da Investigação Paradigma, durante os meses de janeiro a agosto de 2016. 


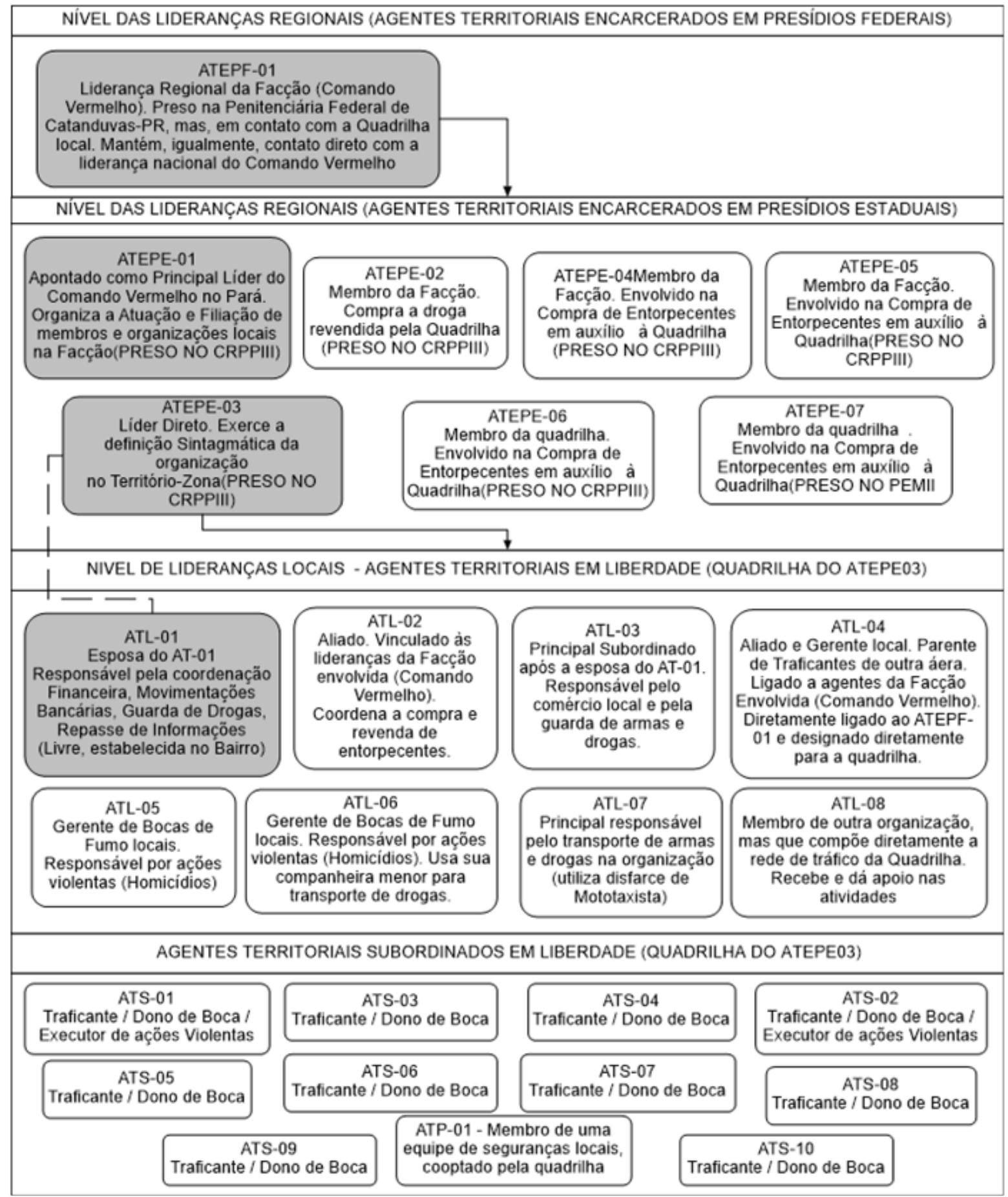

Fonte: Documentos da Pesquisa e registros dos pesquisadores.

Por sua vez, foi nítido que a estratégia propiciou, como também indicado na literatura (OLIVEIRA; COSTA, 2012; AMORIM, 2011, 2015; DIAS, 2011, 2013; SILVA, 2013; LOURENÇO; ALMEIDA, 2013; CAPITANI, 2012; TEIXEIRA, 2015; MARQUES, 2014; ABREU, 2017; VARELLA, 2017; BARCELLOS, 2015; SAVIANO, 2014; MALVASI, 2012a; GODOY; TORRES, 2017), a concentração de funções de liderança entre a cúpula encarcerada e membros do Comando Vermelho, igualmente presos, sobretudo, no que toca aos planos comerciais de drogas e decisões pela tomada de medidas violentas no território. A junção de redes a partir 
de vínculos estabelecidos entre os encarcerados, por sua vez, trouxe consequências à organização territorial local da quadrilha, conforme se expôs adiante.

Evidenciou-se, na escala do bairro das Águas Lindas e adjacências, a presença de lideranças locais em liberdade, em especial, a ATL 01, companheira do líder da organização, ATEPE 03, apontada como gerente financeira do grupo aos quais era incumbida a guarda e comercialização de drogas. Também lhes eram atribuídas as funções de guarda de armas (ATL 03), transporte de drogas e armas (ATL 07, que, inclusive, usaria como disfarce sua profissão de moto taxista) e a prática de homicídios (ATL 05 e ATL 06), dentre outras atividades. Todos residiam, como se depreende do mapa da área (Figura 2), ou no mencionado bairro ou em áreas contíguas ao mesmo. De igual modo, restaram identificados dez Agentes Territoriais Subordinados (ATS 01 a 10), incumbidos do comércio de drogas, bem como, no caso dos ATS's 01 e 02, de execução de ações criminosas - mortes e ataques.

Alguns agentes territoriais do tráfico, inclusive, foram especificamente destinados pelo Comando Vermelho para auxiliar o comércio de drogas no bairro, seja ali se instalando, caso do ATL 08 , seja fornecendo auxílios à distância, caso do ATL 02 e do ATL 04, que, mesmo domiciliados no bairro do Tapanã e no Distrito de Icoaraci - ambos, em Belém-PA, comporiam a rede controlada pela facção na Região Metropolitana.

Além disso, como apontado por Amorim (2011, 2015), Dias e Salla (2013), Lourenço e Almeida (2013), verificou-se que o envio de um dos associados (ATEPF 01) à presídio afeto ao Regime Disciplinar Diferenciado - RDD, ainda antes do início das investigações, não se mostrou suficiente para quebra de sua territorialidade (RAFFESTIN, 1993; HAESBAERT, 2014) com a escala do estudo, uma vez que o mesmo ostentava a condição de depositário de armas do Comando Vermelho, sob posse do ATEPE 01, tendo sido identificados contatos telefônicos entre os dois agentes nos autos do inquérito. Inclusive, foi justamente o encarceramento do ATEPF 01 numa prisão federal que permitiu, conforme mencionado a seguir, o estabelecimento de novas redes a nível nacional e a mudança de afiliação da organização em razão de vantagens econômicas milionárias, destaque-se, que adviriam desta nova rede, evidenciada ao fim da operação.

O caso demonstrou, também, que a relação entre os líderes locais e as facções não estaria permeada, substancialmente, por valores ou ideologias, como apontado por alguns autores (FERRO, 2012; DIAS, 2013; AMORIM, 2011, 2015; 
LOURENÇO; ALMEIDA ET AL, 2013; ABREU, 2017; TAVARES, 2016; MARQUES, 2014; TEIXEIRA, 2015), ao menos, no contexto do Estado do Pará, senão, por nítidos interesses econômicos. Ao final da investigação, por interesses voltados à formação de redes mais lucrativas à quadrilha, observou-se o rompimento de relações do grupo local com o Comando Vermelho - CV, e, uma afiliação ao Primeiro Comando da Capital - PCC, por intermédio de uma quadrilha (Comando Classe A - CCA) que se instalara no município de Altamira-PA, pouco antes da deflagração da fase de campo da Operação Paradigma.

A associação interna e externa também se mostrou assente diante de fato identificado nas investigações: ao longo dos conflitos havidos pela organização com outros agentes territoriais, em seu processo de expansão e combate à reputados milicianos, o líder ATEPE 01, em ligação realizada do presídio ao ATL 07, informou que enviaria alguns associados que se encontrariam cumprindo pena em Regime Semiaberto na Colônia Penitenciária Agrícola de Santa Izabel (contígua ao CRPP III) para reforçar a segurança de bocas de fumo da organização e de seus aliados, os quais ficariam sob o comando dos associados externos e lideranças.

Constatou-se, desse conjunto de informações, que a estratégia de estabelecimento e manutenção de redes e relações junto a agentes sintagmáticos públicos ou privados externos ao cárcere, se afigurava bastante funcional no caso em estudo, já que, o significativo número de associados e aliados identificados, representava uma série de trunfos de poder, tanto no comércio de entorpecentes, quanto, em especial, na imposição da vontade dos líderes através da violência e demais decisões sintagmáticas tomadas a partir do cárcere (SAVIANO, 2014; AMORIM, 2011, 2015; VARELLA, 2012, 2017, DIAS, 2013; LOURENÇO; ALMEIDA, 2013; CAPITANI, 2012; TEIXEIRA, 2015; MALVASI, 2012a; LUCCA, 2016; TAVARES, 2016; ABREU, 2017).

Inclusive, verificou-se no caso, como também foi apontado na literatura (ABREU, 2017; AMORIM, 2011, 2015; MALLART, 2014), a cooptação de agentes territoriais privados para a satisfação de interesses dos agentes do tráfico: foi o caso do ATP 01, vigilante do mesmo grupo territorial de duas das vítimas da ação dos criminosos (ATM's 04 e 05), que ao conceder informações privilegiadas para o assassinato, assumiria, como contrapartida, a direção da referida equipe de vigilância após as mortes, passando a contribuir com as atividades do tráfico.

Além do mais, esta estratégia também foi evidenciada em relação à garantia de visitas por parentes ao ATEPF 01 no Presídio Federal de Catanduvas - PR, sob 
custos da organização, segundo captado em conversas telefônicas, o que, além de demonstrar sua fidelização ao grupo, certamente, favoreceu a permanência de seu vínculo com o território da organização nos mesmos termos destacados pela teoria (DIAS, 2013; AMORIM, 2011, 2015; ABREU, 2017; MALLART, 2014; MALVASI, 2012a; LOURENÇO; ALMEIDA, 2013).

Abaixo (Figura 02) foi possível compreender a presença territorial da organização criminosa na área do estudo. Igualmente, pode-se abstrair uma possível zona de influência territorial da quadrilha, considerando, por exemplo, que 0 corpo da ATM 08 não foi encontrado dentro bairro em destaque, senão, em mata pertencente a bairro contíguo englobado pela área de influência estimada no mapa.

Por sua vez, foi nítida a importância da estratégia de utilização de mediatos para comunicação a partir do cárcere no caso concreto, uma vez que a velocidade de informação dos planos sintagmáticos da organização e das decisões de expansão comercial e aplicação de medidas violentas, concretizadas por associados externos atuantes na escala do estudo, certamente foi potencializada pela preocupação da organização em estabelecer canais comunicativos entre o cárcere e o mundo externo, como bem apontou a literatura ao tratar da funcionalidade e importância de celulares no contexto das facções (SAVIANO, 2014, 2015; AMORIM, 2011, 2015; LOURENÇO; ALMEIDA, 2013; SILVA, 2013; ANDRADE, 2015; BARCELLOS, 2015; ZOMIGHANI JR., 2013; CAPITANI, 2012; TEIXEIRA, 2015; MALVASI, 2012a: FERRO, 2012; MALLART, 2014; GODOY, TORRES, 2017; VARELLA, 2017, ABREU, 2017).

FIGURA 02 - Mapa do bairro das Águas Lindas, em Ananindeua - PA e da possível área de influência da quadrilha, em interação com o domicílio apurado dos Agentes Territoriais da organização (ATL's e ATM's) e local do óbito dos Agentes Territoriais Mortos (ATM's) pela atuação da quadrilha no período de janeiro a agosto de 2016. 


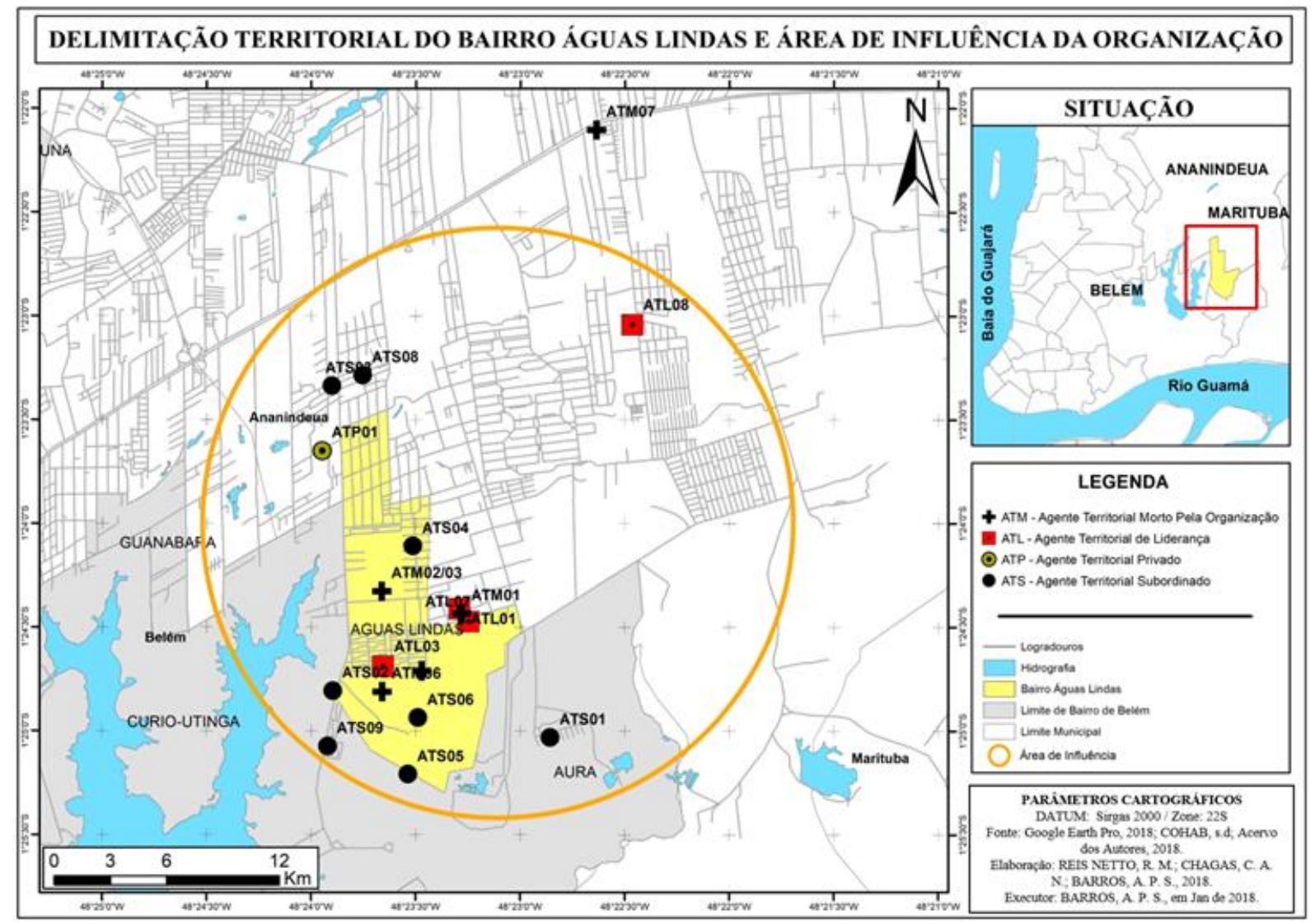

Fonte: Documentos da Pesquisa e registros dos pesquisadores.

Nota: Não foi possível apurar o domicílio no local do ATL 05 (preso em outro município), do ATL 06 e da ATS 07, foragidos durante a investigação, bem como o local do óbito da ATM 08, cujo corpo foi encontrado em coordenada não indicada na investigação dentro de mata no Bairro do Curió-Utinga.

Ao longo da operação, só em relação ao ATEPE 01, foram identificadas cinco possíveis linhas de telefonia celular em utilização. Isso, sem contar os contatos diretamente firmados junto a sua companheira (ATL 01), quando de visitas ao presídio. Como mencionado por Raffestin (1993), a potencialização dos fluxos da informação, com certeza, propiciou uma melhor gestão da energia despendida pela organização na realização de suas atividades locais. Prova disso, foi a identificação nas ligações interceptadas do uso dos celulares para indicação de contas correntes nas quais deveriam ocorrer os depósitos pelas negociações de drogas, sob controle do ATEPE 01 e sob gestão direta de sua companheira, ATL 01, bem como de detalhes das ações violentas a serem realizadas durante as ações de expansão do grupo.

Além disso, permitiu-se a criação de uma rede (Figura 03) que interligou dois presídios da Região Metropolitana de Belém - PA com a área estudada, bem como com membros de outra organização em Belém - PA, que prestavam apoio às atividades do tráfico realizadas pela quadrilha estudada. Deve-se lembrar, também, que a rede local ligava a Região Metropolitana, por meio do ATEPF 01 a outras 
redes nacionais, às quais o mesmo representava um nó (RAFFESTIN, 1993; HAESBAERT, 2014) no Presídio Federal de Catanduvas - PR. Abaixo (Figura 03), é possível observar uma possível delimitação do território-rede (RAFFESTIN, 1993; HAESBAERT, 2014) da quadrilha estudada no caso, que, conforme destacado ao início, se coloca totalmente alheia à lógica zonal preponderante na visão estatal.

FIGURA 03 - Rede territorial instituída pela organização criminosa junto ao território zona identificado em interação com os presídios do PEM II (Marituba - PA), CRPP III (Santa Izabel do Pará - PA) e com membros de outra organização criminosa (sediada em Belém - PA) ao longo dos meses de janeiro a agosto de 2016.

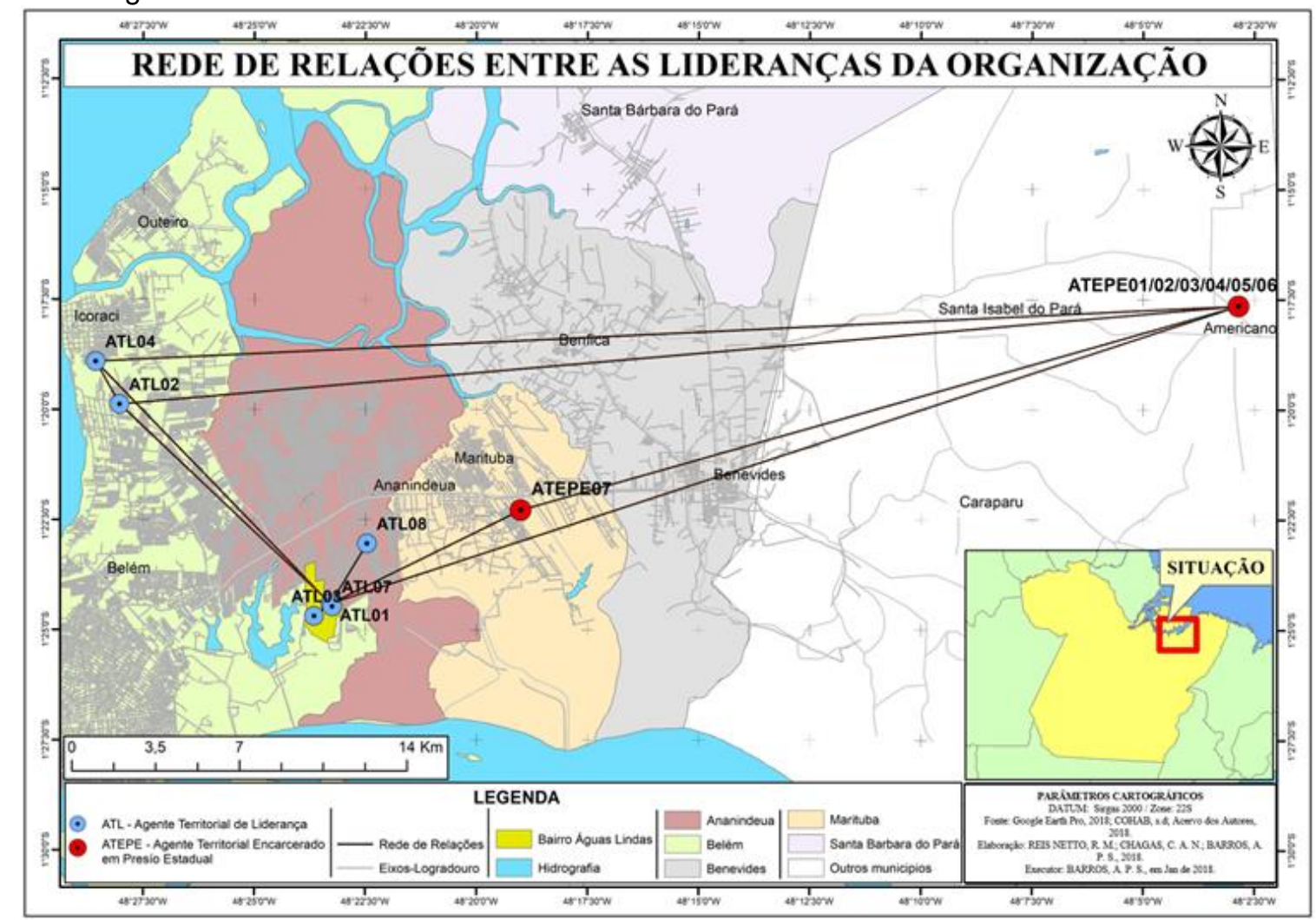

Fonte: Documentos da Pesquisa e registros dos pesquisadores.

Por conseguinte, também foi possível constatar, no caso concreto, o funcionamento da estratégia de enfrentamento direto de agentes sintagmáticos e atingimento de símbolos vinculados ao Poder Público. Em várias das ligações interceptadas, os agentes encarcerados e em liberdade manifestavam a necessidade de realização de agressões a policiais atuantes na região, como forma de expor seu poder no processo de expansão territorial e consolidação de seus agentes nas áreas conflituosas. Deve-se assinalar, entretanto, que estas táticas de violência se encontravam inseridas numa batalha da organização por um domínio territorial (RAFFESTIN, 1993) local, não sendo destinadas somente a agentes públicos da área, senão, a diversos outros atores territoriais: apontou-se no inquérito que os traficantes estariam em conflito com supostas milícias locais, embora não se 
tenha comprovado de fato sua existência, questão excluída desta análise por compor outros inquéritos ainda sigilosos.

Comprovou-se, no entanto, o embate direto da organização com agentes territoriais privados pertencentes a uma empresa de segurança local, cuja atuação representaria uma das maiores formas de resistência a sua expansão. Inclusive, com o desequilíbrio de formas ocasionado pela já afirmada associação no interior do cárcere dos líderes da quadrilha e o Comando Vermelho - CV, este conflito ocasionou a morte de quatro membros desta empresa de segurança (ATM's 02, 03, 04 e 05), em diferentes momentos, como apontado acima, o que foi motivo de comemoração pelos associados em diversas ligações legalmente interceptadas pela polícia civil, até mesmo, junto ao ATEPF 01, foram do Estado.

Todos os fatos ora relatados comprovaram que o manejo, simultâneo e intercruzado (DIAS, 2013) das estratégias (RAFFESTIN, 1993) utilizadas para integração dos presídios às redes externas do tráfico de drogas, condicionaram as redes territoriais locais das seguintes maneiras a seguir destacadas:

a) A associação havida dentro do cárcere propiciou, em primeiro lugar, que a quadrilha angariasse novos agentes territoriais em liberdade, tanto no nível das lideranças, quanto dos subordinados, para exercício de suas atividades (notadamente, o tráfico). Conforme Raffestin (1993), componentes da população caracterizariam trunfos de poder no exercício das mais diversas atividades, no caso, ilícitas, e, ao mesmo tempo, nós integrativos de redes que, com esta associação, seriam ampliadas e otimizadas.

b) Além disso, a integração acima também teria propiciado a ampliação dos recursos (RAFFESTIN, 1993) à disposição da organização, especialmente, armas (utilizadas nos conflitos territoriais necessários à sua expansão), tal como drogas para oferta no comércio instituído na área do estudo e adjacências, ampliando os presumidos lucros da organização, o que também explica seu crescimento local.

c) Os novos recursos, por sua vez, permitiram não só o uso da violência por associados externos de forma mais eficiente, como, sobretudo, que esta violência assumisse aspectos simbólicos expressivos da força da organização perante os demais agentes territoriais locais, o que se constata da violência das ações e grande número de munição empreendida. A área passou a ser identificada como de domínio dos traficantes, assumindo, assim, um aspecto territorial simbólico. 
d) Com isso, conforme manifestado em ligações interceptadas, consolidou-se a expansão territorial pretendida pelos agentes sintagmáticos, bem como, a eliminação de resistências e de agentes territoriais adversos, de maneira especial, os membros da empresa de segurança assassinados durante a investigação.

e) As estratégias comunicativas empregadas (obtenção e uso de celulares, assim como uso de parentes como pombos-correios, especialmente, no caso do ATEPF 01, que recebia constantes visitas em Presídio Federal, sob custos da organização) potencializaram, como dito acima, o fluxo de informações pela rede constituída, permitindo um menor dispêndio de energia para imposição dos planos da quadrilha, do mesmo modo que uma melhor gestão financeira da organização, como visto a cargo da ATL 01.

f) A comunicação também permitiu uma maior efetividade da elaboração dos planos da organização, entre os agentes encarcerados e em liberdade, possibilitando ações mais rápidas e consistentes no controle do território.

g) Com o crescimento periódico, permitiu-se a formação de novas redes, tanto no nível do território estudado, o que foi expresso pelas negociatas de drogas firmadas junto a agentes não identificados em ligações telefônicas interceptadas, como no nível da Região Metropolitana de Belém (como exposto na Figura 03), e, ainda, nos níveis Federal e Regional, como evidenciado, ao fim da operação, a partir do rompimento da organização com o Comando Vermelho - CV, seguida da associação ao Primeiro Comando da Capital - PCC, por meio da organização surgida em Altamira - PA, o Comando Classe A - CCA.

Com isso, como se fosse uma verdadeira empresa (CHAGAS, 2014), a organização buscou alianças, empreendeu recursos e esforços, angariou suportes humanos e, especialmente, procurou uma otimização de suas atividades ilícitas, condicionando as relações territoriais locais de forma a atender seus planos sintagmáticos de poder, confirmando, em muito, indicações constantes da literatura inicialmente consultada.

Ademais, coube a realização de duas observações.

Primeiramente, não se pode constatar, no caso, a utilização da estratégia de estabelecimento de redes comerciais internas do tráfico de drogas, apontada na literatura (REIS NETTO, 2018), não se descartando, entretanto, sua existência, em razão do poder de acesso às redes de drogas constatado, sobretudo, em relação às lideranças do Comando Vermelho - CV no cárcere. 
Por conseguinte, em razão do foco da investigação, mais voltado às consequências territoriais externas da atuação da quadrilha, não foi constatada a estratégia de estabelecimento e manutenção de relações e cooptação de agentes do sistema penitenciário. Por outro lado, observando detalhes das ligações interceptadas junto aos agentes territoriais encarcerados, constatou-se que as mesmas se realizavam nos mais diversos horários e durante significativos lapsos temporais.

Nestes termos, é difícil conceber a não concorrência de agentes penitenciários responsáveis pela vigilância dos encarcerados, principalmente, em razão do fato de que os mesmos se encontravam presos no CRPP III, que ostenta a condição de presídio de segurança máxima, no sistema prisional paraense, sendo presumida, decerto, a realização daquela última estratégia comentada.

\section{Considerações Finais}

Atendendo ao propósito de comparação e verificação dos postulados teóricos inicialmente colhidos, o presente estudo de caso de natureza instrumental, seguindo os cuidados metodológicos e técnicos especificados, ao fim, comprovou que as estratégias manejadas pelo tráfico para integração dos presídios às redes territoriais externas, de fato, são capazes de propiciar uma série de novos vínculos e, por meio destes, angariar diversos recursos e trunfos de poder que, se bem empregados, podem favorecer e otimizar a ação dos agentes territoriais do tráfico de drogas em seus respectivos territórios, desequilibrando relações de poder e, com isso, condicionando e trazendo significativas consequências à territorialidade havida num determinado espaço.

Por óbvio, a utilização simultânea e intercruzada das referidas estratégias variará conforme cada organização criminosa e seus respectivos planos sintagmáticos de poder, bem como, de acordo com especificidades de cada espaço onde estas venham a se estabelecer elementos também condicionante daquelas, conforme afirma Raffestin (1993).

No entanto, a possibilidade de influência nas relações de poder estabelecidas no espaço ora constatada, certamente, constitui um fato que assume caracteres universalizáveis, sendo assim, constatação importante à segurança pública e à ciência social, de modo que o movimento estratégico de agentes territoriais encarcerados se afigura como elemento merecedor de especial atenção, 
contrariando o senso comum de que, com o seu simples aprisionamento, seriam desconstituídas as suas relações de territorialidade e redes originárias.

Ao passo, também foram encontradas algumas peculiaridades no teor do caso, diferenciadas dos apontamentos literários: a) a negação da importância dos aspectos ideológicos inerentes às facções, destacados na literatura, o que restou evidente diante da fácil desvinculação da quadrilha estudada ao Comando Vermelho, seguida da afiliação ao Primeiro Comando da Capital - PCC, por intermédio do Comando Classe A - CCA, conforme interesses econômicos e sem maiores conflitos aparentes; b) a ocorrência do suposto deslocamento de agentes territoriais do tráfico, encarcerados no regime semiaberto, para atendimento aos interesses externos da organização, dado até então não encontrado na literatura sobre o tema.

Estes dados diferenciados, por sua vez, podem representar peculiaridades do tráfico no Estado do Pará, ou, ainda, uma transformação dos valores regentes das facções ao redor do país, que, como informado por autores como Amorim (2011, 2015) e Dias (2013), cada vez mais se voltam para uma economia do crime, em abandono à ideologia de paz entre os ladrões, valendo-se cada vez mais de falhas do sistema jurídico-penal e penitenciário para protagonismo de suas ações territoriais.

Em todo caso, é recomendada a realização de outros estudos de caso instrumentais em torno de casos emblemáticos, como o presente, para fins comparativos a respeito das hipóteses então renovadas sobre o assunto, bem como acompanhamento da evolução em uma atividade, na medida do possível, preditiva das ações das organizações criminosas do século XXI.

\section{REFERÊNCIAS}

ABREU, A. Cocaína - A rota caipira: O narcotráfico no principal corredor de drogas do Brasil. Rio de Janeiro: Record, 2017.

ALMEIDA, M. A. B.; GUTIERREZ, G. L.; CHICARELI, S. C.; CIDRO, D. Lazer e o presídio: aspectos de um paradoxo. São Paulo: EACH, 2013.

ALVEZ-MAZZOTTI, A. J. Usos e Abusos do Estudo de Caso. Cadernos de Pesquisa, v. 36, n. 129, p. 637-651, 2006.

AMORIM, C. Comando Vermelho: a história do crime organizado. Rio de Janeiro:

BestBolso, 2011.

AMORIM, C. CV - PCC: A irmandade do Crime. 13. ed. Rio de Janeiro: Record, 2015. ANDRADE, E. L. Sem Derramamento de Sangue: Religião e Violência na Prisão. Revista de Campo de Ciências Sociais, n. 19, p. 155-176, 2015.

BARCELLOS, C. Abusado: O dono do morro Santa Marta. 26. ed. Rio de Janeiro: Record, 2015.

BAUMAN, Z. O Mal-estar da Pós-modernidade. Rio de Janeiro: Zahar, 1998. 
BRANDÃO, H. H. N. Introdução à Análise de Discurso. 3. Ed. Campinas: Unicamp, 2012. CAPITANI, R. O meio ambiente prisional brasileiro e a saúde do preso: um estudo no Presídio Estadual de Bento Gonçalves. Dissertação de mestrado. Rio Grande Do Sul: Universidade de Caxias do Sul, 2012.

CARVALHO, S. A política Criminal de Drogas no Brasil: Estudo Criminológico e Dogmático da Lei 11.343/06. 8. ed. São Paulo: Saraiva, 2016.

CHAGAS, C. A. N. Geografia, segurança pública e a cartografia dos homicídios na região metropolitana de Belém. Boletim Amazônico de Geografia, v.1, n. 1, p. 186-204, 2014. D'ELIA FILHO, O. Z. Acionistas do nada: Quem são os traficantes de drogas. Rio de Janeiro: Revan, 2014.

DIAS, C. N. PCC: Hegemonia nas Prisões e Monopólio da Violência. São Paulo: Saraiva, 2013.

DIAS, C. N.; SALLA, F. Organized Crime in Brazilian Prisons: The Example of the PCC. International Journal of Criminology and Sociology, v. 2, n. 2, p. 397-408, 2013. DIVINO, S. B. S.; SIQUEIRA L. A. V. C. de. O direito ao esquecimento como tutela dos direitos da personalidade na sociedade da informação: uma análise sob a ótica do direito civil contemporâneo. Revista eletrônica do curso de direito da UFSM, v. 12, n. 1, p. 218237, 2017.

FERRO, A. L. A. Uma proposta legislativa para o enfrentamento da criminalidade organizada. De jure: Revista Jurídica do Ministério Público do Estado de Minas Gerais, v. 11, n. 19, p. 85-111, 2012.

FITZ, P. R. Cartografia Básica. São Paulo: Oficina dos Textos, 2008.

FREITAS, W.; JABBOUR, C. Utilizando estudo de caso(s) como estratégia de pesquisa qualitativa. Estudo \& Debate, v. 18, n. 2, p. 07-22, 2011.

GODOY, G.; TORRES, B. Baladas Proibidas: A história do rei do ecstasy. Rio de Janeiro: Record, 2017.

HABERMAS, J. Dialética e Hermenêutica: Para a crítica da Hermenêutica de Gadamer. Porto Alegre: LP\&M, 1987.

HAESBAERT, R. Viver no Limite: Território e Multi/Transterritorialidade em tempos de insegurança e contenção. Rio de Janeiro: Bertrand Brasil, 2014.

LAKATOS, E. M.; MARCONI, M. de A. Fundamentos de Metodologia Científica. 7. ed. São Paulo: Atlas, 2016.

LOURENÇO, L. C.; ALMEIDA, O. L.. "Quem mantém a ordem, quem cria desordem".

Tempo Social, v. 25, n. 1, p. 37-59, 2013.

LUCCA, D. Diário de um policial. São Paulo: Planeta, 2016.

MALLART, F. Cadeias Dominadas: A fundação CASA, suas dinâmicas e as trajetórias de jovens internos. São Paulo: Terceiro Nome, 2014.

MALVASI, P. A. Interfaces da Vida Loka: um estudo sobre jovens, tráfico de drogas e violência em São Paulo (Tese). São Paulo: USP, 2012a.

MARQUES, A. Crime e Proceder: Um experimento antropológico. São Paulo: Alameda, 2014.

MARTINELLI, M. Mapas da geografia e cartografia temática. 6. ed. São Paulo: Contexto, 2014.

MINAYO, M. C. S. Hermenêutica-Dialética como Caminho do Pensamento Social. In: MINAYO, M. C. S. Caminhos do Pensamento: epistemologia e método. Rio de Janeiro: Editora Fiocruz, 2002.

MINAYO, M. C. S. Introdução: conceito de avaliação por triangulação de Métodos. In: MINAYO, M. C. S.; ASSIS, S. G.; SOUZA, E. R. Avaliação por Triangulação de Métodos: abordagem de programas sociais. 20. ed. Rio de Janeiro: Editora Fiocruz, 2005.

O GLOBO. Entenda a guerra na Favela da Rocinha. Disponível em: <https://oglobo. globo.com/rio/entenda-guerra-na-favela-da-rocinha-21836363>. Acesso em: 01.01.2018. OLIVEIRA, G. F.; COSTA, G. V. L. A cidade e os informantes: inserção etnográfica nos pontos de venda de drogas da cidade de. Composição: Revista de Ciências Sociais da Universidade Federal do Mato Grosso do Sul, v. 11, n. 11, p. 2-24, 2012.

OLSEN, W. Coleta de Dados: Debates e Métodos Fundamentais em Pesquisa Social. Porto Alegre: Penso, 2015. 
RAFFESTIN, C. Por uma Geografia do Poder. São Paulo: Ática, 1993.

REIS NETTO, R. M. Além das grades: A integração dos presídios às redes territoriais do tráfico drogas (dissertação). Belém: PPGSP/UFPA, 2018.

REIS NETTO, R. M.; CHAGAS, C, A, N. A associação externa como forma de integração dos presídios às redes externas do tráfico: a percepção dos agentes territoriais da segurança pública no Pará. Revista Estudos Geográficos. V. 16, N. 2, P. 157-173. 2018a. REIS NETTO, R. M.; CHAGAS, C. A. N. Associação interna como forma de integração dos presídios às redes externas do tráfico: a percepção dos agentes territoriais da segurança pública no estado do Pará. Direito GV, v. 15, n. 2, p. 1-20. 2019a.

REIS NETTO, R. M.; CHAGAS, C. A. N. A percepção de agentes da segurança pública a respeito do enfrentamento do poder público como estratégia de integração dos presídios às redes externas do tráfico. In: TRINDADE, C. M. et al. Segurança Pública: ética e cidadania. Curitiba: CRV, 2019b.

REIS NETTO, R. M.; CHAGAS, C. A. N. Estratégias e mediatos utilizados pelo tráfico de drogas para integração dos presídios às redes territoriais externas: uma revisão da literatura. Revista Opinião Jurídica, v. 16, n. 23. p. 110-139. $2018 \mathrm{~b}$.

RODRIGUES, T. Política e Drogas nas Américas. São Paulo: EDUC/FAPESP, 2004.

SAVIANO, R. Zero, Zero, Zero. São Paulo: Companhia das Letras, 2014.

SAVIANO, R. Gomorra: a história real de um jornalista infiltrado na violenta máfia napolitana. 10. ed. Rio de Janeiro: Bertrand Brasil, 2015.

SILVA, L. D. A lei no 9.034/95 e as organizações criminosas brasileiras. THEMIS, v. 11, n. 11, p. 267-280, 2013.

STEIN, E. Dialética e Hermenêutica: Uma controvérsia sobre o método em filosofia.

Síntese, v.1, n. 29, p. 21-48, 1983.

TAVARES, A. S. Mulheres e tráfico de drogas no Distrito Federal: Entre os números e a invisibilidade feminina. Rio de Janeiro: Lumen Juris, 2016.

TEIXEIRA, A. Construir a delinquência, articular a criminalidade: um estudo sobre a gestão dos ilegalismos na cidade de São Paulo (Tese). São Paulo: USP, 2015.

UOL. Guerra entre PCC e CV causou rebelião em vários presídios do país, diz secretário de RR. Disponível em: <

https://noticias.uol.com.br/cotidiano/ultimasnoticias/2016/10/17/

guerra-entre-pcc-e-cv-causou-rebeliao-em-varios-presidios-do-pais-diz-secretario-de-

rr.htm>. Acesso em: 01.01.2018.

UOL. Rebelião em Goiás foi motivada por disputa entre PCC e o Comando Vermelho.

Disponível em: <https://noticias.uol.com.br/cotidiano/ultimas-noticias/2018/01/04/rebeliao-

em-goias-foi-motivada-por-disputa-entre-pcc-e-o-comando-vermelho.htm>. Acesso em:

04.01.2018.

VARELLA, D. Carcereiros. São Paulo: Companhia das Letras, 2012.

VARELLA, D. Prisioneiras. São Paulo: Companhia das Letras, 2017.

VENTURA, M. M. O estudo de caso como modalidade de pesquisa. Revista SOCERJ, v. 5, n. 20, p. 383-386, 2007.

ZOMIGHANI JR., J. H. Conexões geográficas e segregação sócio-espacial pelo uso das prisões no Estado de São Paulo. GEOUSP - Espaço e Tempo, n. 35, p. 97-114, 2013.

\section{NOTAS DE AUTOR}

\section{CONTRIBUIÇÃO DE AUTORIA}

Roberto Magno Reis Netto- Concepção. Coleta de dados, Análise de dados, Elaboração do manuscrito, revisão e aprovação da versão final do trabalho.

Clay Anderson Nunes Chagas - Concepção. Coleta de dados, Análise de dados, Elaboração do manuscrito, revisão e aprovação da versão final do trabalho.

FINANCIAMENTO

Não se aplica. 
Os mapas apresentados no estudo (Figuras 2 e 3) foram elaborados pelos autores e executados com a participação de Alexandre Patrício Silva Barros, que consentiu, na qualidade de membro do Laboratório de Pesquisa em Geografia da Violência e do Crime - LAB-GEOVCRIM/UEPA, com o uso das imagens.

\section{APROVAÇÃO DE COMITÊ DE ÉTICA EM PESQUISA}

Não se aplica.

\section{CONFLITO DE INTERESSES}

Não há.

\section{LICENÇA DE USO}

Este artigo está licenciado sob a Licença Creative Commons CC-BY. Com essa licença você pode compartilhar, adaptar, criar para qualquer fim, desde que atribua a autoria da obra.

\section{HISTÓRICO}

Recebido em: 16-11-2018

Aprovado em: 24-05-2019 